Mesa 3

\title{
La publicidad desde el otro lado de la cocina. Observaciones y constataciones de un fenomenólogo
}

\author{
Joan $\operatorname{COSTA}^{1}$ \\ Universitat Autónoma de Barcelona
}

\section{RESUMEN:}

Las relaciones ambiguas entre Arte, Publicidad y Consumo muestran que la influencia del Arte no es la única que incide en la Publicidad: en todo caso, no es cualitativa ni estadísticamente predominante. Se estudian aquí los modos como los signos del Arte -y del no arte- se introducen en el lenguaje publicitario, así como el peso del Arte en la Publicidad, en una pequeña muestra.

PALABRAS CLAVE: Arte, publicidad, consumo, comunicación, percepción, información, diseño

TITLE: Advertising from the other side of the kitchen. Observations and findings of a phenomenologist.

\begin{abstract}
:
The ambiguous relations between Art, Advertising and Consumption shows that the influence of art is not the only one that has an impact on the advertising: in any case, it is not qualitatively or statistically predominant. We study here the modes as the signs of Art --and the no-art-- are entered in the advertising language, as well as the weight of the art in advertising, in a small sample.
\end{abstract}

KEY WORDS: Art, advertising, consumption, communication, perception, information, design

\section{Introducción}

La ciencia es la búsqueda de la verdad a través de la crítica. Karl Popper

1 Autodidacta. Comunicólogo, sociólogo, investigador, metodólogo y consultor. Profesor invitado en varias universidades europeas y americanas. Autor de más de 30 libros y centenares de artículos. Doctor honoris causa Universitat Jaume I, España, y Universidad Siglo 21, Argentina. Correo electrónico: joancostasola@gmail.com. 
El propósito de este trabajo no es defender una tesis preexistente ni tampoco la contraria sobre las relaciones entre A, P y C, sino el deseo de contribuir a la discusión con espíritu científico.

Lo que la intuición dice de entrada acerca de la tríada Arte, Publicidad y Consumo es un buen punto de partida. Podemos sintetizarlo con esta ecuación:

$\begin{array}{cc}\text { Arte }> & <\text { Publicidad }<\quad>\text { Consumo } \\ \text { donde el grafo }> & <\text { significa oposición, y }<>\text { interacción }\end{array}$

Dicho con otras palabras: no hay transitividad entre A y $\mathrm{P}$, por lo que tampoco la hay entre A y C.

En cambio, sí hay transitividad de $\mathrm{P}$ a $\mathrm{C}$. Y no solo eso: hay interacciones intrínsecas entre ambos términos. Hay relación causal e incluso interdependencia entre $\mathrm{P}$ y $\mathrm{C}$, y viceversa. Ambos están hechos el uno para el otro. El uno con el otro. Han sido tejidos juntos (principio de complejidad, según el amigo Morin). Y así son inseparables: $\mathrm{P}$ y $\mathrm{C}$ se condicionan, se determinan y se autorregulan.

Lo cual no es en absoluto lo que sucede entre A y P, que nacieron autónomos uno del otro. Pero las razones de tiempo y lugar no son las únicas que marcan las diferencias. No hay más que evocar la naturaleza, los motivos, la génesis, las circunstancias socioculturales y el lenguaje de A, para constatar que se encuentran en las antípodas de aquéllas que definen a P. Lo cual es obvio.

Sin embargo, lo que ha sido tejido junto atrae la complejidad y se hace híbrido, multicultural y más complejo: evoluciona, se reorienta y absorbe propiedades de otras fuentes. Y así, A y P toman caminos diferentes de aquellos que los separaron en sus orígenes. Caminos y rodeos que pueden ser convergentes o divergentes según los contextos en que se producen, y que pueden incidir en $\mathrm{C}$.

\section{Arte}

En el origen, el Arte apareció de la mano de sapiens unos 20.000 años antes de nosotros, y ahí están, todavía, los bisontes de Altamira y los tropeles de Lascaux.

El Arte es intrínsecamente inútil, en el sentido funcional, utilitarista u operacional del término, a diferencia del hacha de sílex que sí es intrínsecamente útil. La finalidad del Arte es él mismo. El hacha es un instrumento. El Arte es un absoluto, pero que puede ser instrumentalizado, imitado, falsificado y convertido en mercancía -aunque estas siempre serán utilizaciones ulteriores, ajenas al origen del Arte y a sus fines.

La obra de arte no surge de una exigencia de supervivencia -como el hacha-, sino de un impulso íntimo de sapiens: ser psicológico y ser social al mismo tiempo. 
El Arte emana de la libertad creadora y es una manifestación original del individuo expresada por la vía de la abstracción simbólica, ese lenguaje ambiguo y complejo.

La obra es ejecutada con el mínimo de recursos materiales y gráficos para la máxima expresividad. Y está vinculada a las circunstancias de su tiempo, del que ella es un reflejo cultural. He aquí los rasgos que definen el Arte en sus orígenes.

\section{Arte y Publicidad}

La historia de la Publicidad moderna muestra que fueron los artistas plásticos sus creadores. Con el Cartel inventaron al mismo tiempo el medio, el mensaje y el lenguaje: el medio exterior, el mensaje sintético y el lenguaje visual instantáneo. Las tres propiedades que definen la especificidad del Cartel.

Los artistas plásticos trasladaron así la verticalidad de la Pintura (que había atravesado el mural, la tabla, el vitral, el tapiz, el cuadro) con su pregnancia, sus formas seductoras y sus colores llamativos para llevarlos a la vía pública, en una sociedad que sería cada vez más y más urbana. En 1866, Jules Chéret había empezado a producir en París carteles litográficos a gran tamaño y en color. Poco antes, Émile de Girardin había lanzado el periódico La Presse, y con él inventó el Anuncio inserto entre las páginas de las noticias. La Publicidad -por medio del Cartel y del Anuncio- nació con la imprenta y la litografía, o sea la industria gráfica que fabrica Mensajes para ayudar a otra industria: la que fabrica Consumidores.

En el origen, no hay efectivamente transitividad entre A y P. Pero cuando esta nace por imperativo de la economía industrial, surgen conectores de A que transfieren sus signos a P. Sin embargo, y esto es importante constatarlo, el conector no es el Arte en tanto que obra del genio del artista. El conector es el artista, ser humano que, como tal, no solo ni siempre está produciendo arte. Cuando García Lorca pone un telegrama no hace poesía. La conexión que los artistas establecen con la Publicidad consiste en trasladar al Cartel las habilidades, la factura, el trazo y el estilo propios de su trabajo como artistas. Tales rasgos visibles también los apreciamos en sus obras artísticas, porque esos rasgos son su modo personal de expresión o de «escritura» (igual que cada quien tiene su caligrafía), y que con la publicidad se aplican a estetizar y dar respuesta a necesidades funcionales, que no surgen libremente del interior del ser. El Cartel no es un cuadro más entre el conjunto de la obra del artista. Es diferente en su misma esencia. Es un Anuncio.

Es cierto que los artistas también trabajan por encargo: retratos de personajes, paisajes para decoración de mansiones (como en la Venecia de Van Wittel y Canaletto), pero estas obras no tenían otro destino que el goce de sus mismos clientes. Lo cual es sustancialmente distinto del encargo publicitario, cuyo destinatario es un tercer público masivo: el mercado de consumo, y cuyo fin no es el disfrute estético. 
Esta dependencia del artista, que transfiere sus habilidades y su estilo a una exigencia publicitaria - una instrumentalización- implica una serie de condicionamientos técnicos y económicos, empezando por el soporte papel, que le es impuesto; su tamaño determinado por la máquina litográfica; la técnica de reproducción múltiple; los costes de producción dependiendo del número de tintas, así como la supeditación a un objetivo de rentabilidad y a un tema concretos, que son lo que motiva el anuncio.

Así, la Publicidad introduce en el Cartel un discurso lingüístico (palabras, oraciones, argumentos, imperativos) con lo cual el anuncio, si bien surge del artista plástico, es ajeno al Arte, mensaje icónico. Es el discurso funcional de la información textual persuasiva o las apelaciones que instan al consumo. Así, los elementos simples del Arte, que han sido introducidos en el mensaje, operan la conexión indirecta y siempre relativa de esos signos del Arte con el Consumo. Pero en esta invasión lingüística a un arte que es sustancialmente visual, icónico, se incorpora subrepticiamente un elemento funcional que es no solo ajeno sino incluso opuesto al lenguaje icónico: es la inclusión del Código, es decir, un sistema lingüístico de signos que, a diferencia de como se percibe la imagen -de manera inmanente y espontánea-, dichos signos solo son asequibles, decodificables, o sea inteligibles, mediante la previa alfabetización del individuo y el conocimiento de la lengua utilizada en ese mensaje.

El texto no solo contradice las imágenes, sino que él mismo es roto por la contradicción interna: de lo que ha sido hecho para ser visto y lo que lo ha sido para ser descifrado. Este discurso lingüístico y su sistema codificado que invade parte del espacio icónico-supuestamente espacio propio del Arte- para introducir una información utilitaria condiciona la imagen y al propio artista.

Sin embargo, reconozcamos que los enlumineurs medievales incluían inscripciones como ornamentos de las estampas. Pero, ¿son comparables la intención y el significado de estas inscripciones con los textos de un copy en los anuncios? Por otra parte, hay que considerar la constancia en el tiempo de las inscripciones en las estampas -que, por cierto, Dürer llevó a algunos de sus cuadros- $y$, por el contrario, la inevitable persistencia de los textos en la publicidad.

\section{Publicidad y Consumo}

La finalidad de $\mathrm{P}$ nunca es ella misma, ni es un medio de expresión personal libre, como A, sino el trabajo de un equipo de técnicos y especialistas regido por un objetivo común. La Publicidad, como el hacha, es instrumental. Está hecha para obtener una respuesta del público en términos de Consumo. Y ella no tiene otra ideología que la eficacia. La cual se mide en signos monetarios. 
El publicitario no es un artista. Es un mediador entre su cliente -quien fija objetivos y condiciones- y el consumidor que, en tanto que destinatario de un mensaje persuasivo o coercitivo, es libre de aceptarlo o rechazarlo.

La Publicidad procede de la ideología capitalista-productivista en la era industrial (siglos XIX-XX). No se produce porque se consume, sino que se consume porque se produce, y es preciso que de algún modo se refuerce la correlación entre ambos términos. Así, si las motivaciones para el consumo no existen o son demasiado débiles, hay que crearlas o amplificarlas. Se establece entonces un doble ciclo en el que cada uno de los elementos - la fábrica y el mercado- se hallan conectados a través de los productos y los salarios, las ventas y el trabajo. Y el cometido de la Publicidad consiste en transformar los deseos latentes en necesidades y crear así una bomba auxiliar que acelere la circulación de los productos $\mathrm{y}$, por tanto, las ventas. Esta bomba auxiliar, que surge de las necesidades de una producción masiva, tendrá como fin crear un sistema de consumo masivo: el mercado.

De esta exigencia surge la Publicidad. Y así se crea el circuito que se realimenta a sí mismo. Es el ciclo de producción-consumo. En la medida que consumir es destruir, el ciclo funciona por el mecanismo de producción-destrucciónproducción... y así indefinidamente. La aceleración del consumir empuja la aceleración del producir. Y en este mecanismo juega la Publicidad.

$\mathrm{Su}$ estrategia es la difusión, y ésta se apoya en medios y soportes técnicos que le son ajenos (prensa, radio, cine, televisión, vehículos de transporte, pasillos del metro, marquesinas, carteleras, internet, etc.), y emplea una táctica de segmentación-distribución-repetición de los mensajes, los cuales, en su misma difusiónprofusión se agotan y se vuelven obsoletos. Igual como en el modelo industrial la producción empuja al consumo que empuja la producción, etc., también la difusión publicitaria empuja la obsolescencia que empuja la creatividad que empuja la obsolescencia que empuja la renovación constante... y así indefinidamente.

Puede argüirse que hay Publicidad en ciertos museos (los museos del Cartel, por ejemplo), igual como hay productos industriales fabricados en serie (las máquinas de escribir Olivetti en el MOMA). Pero no se negará que tal operación consiste en una evidente descontextualización del tiempo y el lugar en que estos artefactos fueron hechos: una rareza. Ni los carteles ni las máquinas de escribir fueron hechos para ser exhibidos, contemplados y conservados en los museos. Tampoco el hecho de que allí convivan con Breuguel, Velázquez o Rodin convierte estas piezas en Arte. Lo que se exhibe en el museo es el residuo cultural de los carteles y los objetos: son las formas, el estilo, la estética y su correspondencia con la cultura de su época. Pero han perdido sus funciones: el mensaje semántico puntual y la operatividad. Justo aquello que justifica su existencia en una sociedad determinada. Sin embargo, formas, estilo y estética no son atributos exclusivos del Arte. 


\subsection{El consumo en la teoría de los actos}

Retomemos la idea de lo que, desde el industrialismo, significa «consumir». Considerando toda forma de consumo como una acción energética del individuo (teoría de los actos), daremos un breve rodeo para acudir a la Micropsicología, que es el estudio de los pequeños actos de la vida cotidiana ${ }^{2}$.

La idea central de la Micropsicología es la noción de coste generalizado, que observa una acción -grande o pequeña- como una sucesión de microactos que constituyen un acto, y una secuencia de actos que conforman una acción. La noción de coste generalizado incluye cinco componentes: 1, coste financiero: la compra del producto; 2, coste temporal: suma de unidades de tiempo ocupado en trasladar y consumir el producto; 3 , coste energético: cantidad de intensidad física en el transporte y el consumo; 4, coste intelectual: esfuerzo por comprender (modo de empleo, tentativas); 5, coste psicológico: vinculado a la expectativa (microfrustración, microtemor, microsatisfacción).

Partiendo de estas variables, observamos en primer lugar la dimensión 2, coste temporal, como un aspecto del acto de consumir, que puede ser breve (usar y tirar) o dilatado (conducir el coche). Entre ambos extremos de la línea temporal imaginaria del consumo del objeto -lo que la economía política llama «bienes»- establecemos una escala de grados que incluyen dos magnitudes: el coste temporal, 2, y el coste energético, 3 , en grados relativos, que medirán la duración de la acción de consumir y la intensidad energética de esta acción. Para no sobrecargar la propuesta, prescindiremos del coste intelectual y el coste psicológico.

La confluencia de estas dos variables retenidas en determinados grados de la escala corresponderá a una mayor o menor duración e intensidad de la acción. Estos valores definen diferencias apreciables: no se consume un yogur (destrucción) como se consume un mueble de anticuario (utilización, exhibición). Así, podemos ordenar, de mayor a menor efecto de destruir, usar, gastar o desgastar y utilizar estas designaciones de los actos de consumir con más precisión. Dicha escala puede formularse así:

2 A. Moles (1977), Theorie des actes, Casterman, Tournai y (1976), Micropsychologie et vie quotidienne, París, Denoël/Gontier. 


\begin{tabular}{|c|c|}
\hline Consumo material & \\
\hline Modos: destruir / usar / gastar / utilizar & Modo \\
\hline Tiempo: $-\longrightarrow$ & Tien \\
\hline \multicolumn{2}{|c|}{ Ejemplos de consumo material: } \\
\hline \multicolumn{2}{|c|}{$\begin{array}{l}\text { Destruir: bienes de consumo diario y constante como alimentos, bebidas y otros } \\
\text { relacionados o no con estos. }\end{array}$} \\
\hline \multicolumn{2}{|c|}{$\begin{array}{l}\text { Usar: productos de usar y tirar de uso frecuente: cepillos de dientes, llaves, } \\
\text { bricolaje, desechables. }\end{array}$} \\
\hline \multirow{3}{*}{\multicolumn{2}{|c|}{$\begin{array}{l}\text { Gastar: desgaste de alfombras, escobas, artículos de viaje, zapatos, neumáticos. } \\
\text { Utilizar: electrodomésticos, equipos de música, coches, impresora, mobiliario. } \\
\text { Ejemplos de consumo psicológico: }\end{array}$}} \\
\hline & \\
\hline & \\
\hline \multicolumn{2}{|c|}{$\begin{array}{l}\text { Abandonar: artículos de moda («la moda es lo que pasa de moda», según Coco } \\
\text { Chanel). }\end{array}$} \\
\hline ec & \\
\hline
\end{tabular}

La herramienta específica para la evaluación de los estímulos intangibles nos la proporciona la teoría matemática de la Información, que permite medir el nivel de complejidad, de originalidad, de inteligibilidad, de información versus redundancia; o de abstracción de un sistema semiótico, como por ejemplo, un anuncio.

\subsection{Arte y consumo}

En efecto, un hacha, un automóvil o un ordenador no son antes que cualquier otra $\cos a$, sistemas semióticos, sino objetos construidos para ejecutar funciones: cortar; desplazarse sin fatigarse; procesar datos. Están hechos para sustituir el esfuerzo físico o mental del usuario, lo cual no impide que, en tanto que objetos que chocan con nuestros ojos, ellos mismos significan lo que son porque han sido in-formados (dotados de forma que informa) para que los reconozcamos.

En otra parte me he extendido en el estudio del «consumo televisivo». Es evidente que tal modo de «consumir»-información, significados, valores- no encaja en las coordenadas tradicionales del consumo material ni del consumo psicológico de funciones. Todo mensaje es, antes que cualquier otra cosa, un sistema semiótico elaborado para transmitir, por medio de formas y colores, sensaciones, emocio- 
nes, choques psicológicos (Arte), o para obtener resultados en términos de inducción al consumo (Publicidad).

Nadie lee dos veces el mismo periódico. La información fue absorbida, registrada o integrada -según los casos- a la primera. Y, con ello, la novedad, la noticia, es decir los contenidos, están en nuestra mente, pero la información sigue allí intacta y puede permanecer años en una hemeroteca sin que haya sido destruida, usada, gastada. ¿Será utilizada? Es algo que no sabemos porque forma parte de una conducta no observable: lo que hace este señor después de leer el periódico, ¿es consecuencia de algo que acaba de leer? ¿Quedó esto archivado en su memoria o ya ha sido olvidado?

Los contenidos semióticos (semánticos, estéticos, originales o complejos) de una información escrita como una obra literaria o un manual de instrucciones, o icónica como un anuncio, no son consumidos como se consume un objeto: por sus funciones. Los contenidos semióticos transportan Información. «La información es información, no es materia ni energía», sentenció Norbert Wiener. Claro que hay aquí un aspecto psicológico, emocional que incide en los efectos de la percepción: abandonar, olvidar, retener o manifestar de algún modo la reacción al mensaje, ya sea por medio del acto de la opinión. Toda acción provoca una reacción.

En el caso de la experiencia artística, el contenido de la obra interpretado por el contemplador constituye un proceso metabólico, que transforma lo experimentado (racional o emocionalmente) en cultura. Si se trata de un mensaje científico, la metabolización transforma lo experimentado en conocimiento. Si consideramos un mensaje distractivo (entretenimiento) o persuasivo, en última instancia puede convertirse en un residuo cultural en el nivel de la conducta consumista.

Por eso, el Arte, como los anuncios, las noticias y los espectáculos, no se consumen: se absorben, se experimentan (o se abandonan). Pero siempre serán metabolizados en cultura personal, colectiva o masiva. Depende.

\section{Signos de artistas en los anuncios}

En el tema del Consumo, nuestro interés investigador pronto se agota, pues es más que evidente su relación intrínseca con la Publicidad, de lo que ya hemos hablado precedentemente. El debate, pues, regresa a la cuestión del Arte.

Cuando el artista pinta un cartel o hace un filmlet publicitario partiendo de la imposición finalista de su cliente-anunciante, reconocemos en ese mensaje la forma de sus signos, al margen del contenido textual o discursivo. El artista se copia a sí mismo. Las escenas que Toulouse-Lautrec o Alphonse Mucha pintan en sus carteles, o la serie de filmlets que Federico Fellini produce para el Banco di Roma, ofrecen mensajes persuasivos, inductivos cuya intencionalidad se sintetiza en los textos que los acompañan: «Divan Japonais, 75 rue des Martyrs» (Toulou- 
se-Lautrec); «Salon des Cent. XX Exposition (mars-avril 1896) Hall de la Plume, 31 rue de Bonaparte-Paris. Entrée: 0,50» (Mucha), o «Si quieres dormir tranquilo hazte cliente del Banco di Roma» (Fellini).

Entre las muchas, evidentes y lógicas diferencias que se encuentran si se comparan estos mensajes publicitarios, en el caso concreto de la producción filmica del autor, se ve que esos filmlets han sido concebidos como una miniserie donde todos ellos desembocan en la apelación publicitaria citada más arriba. La táctica no es la del Arte ni del arte de Fellini, sino de las campañas publicitarias - lo que llamamos difusión (de un mismo mensaje) en diversidad-, y con esta táctica, los anuncios se relacionan entre sí y con la marca mediante la sistemática repetición de idéntico final e idéntico cierre: la imagen de la sede central del Banco con el eslogan y el logotipo en sobreimpresión.

Lo que el genio de Fellini ha trasladado a estos filmlets son las situaciones, el casting, la atmósfera, el sentido caricaturesco, e incluso la música habitual de Nino Rota. Estos recursos -que son las constantes fellinianas de toda su obra, con independencia de cuáles sean los relatos- poseen tal personalidad, tal poder de evocación, tal expresividad de ese universo típicamente felliniano, que logran enmascarar -o justificar- la estructura de la técnica publicitaria. Y es la pregnancia, el estilo, la retórica fílmica y el mundo formal del maestro lo que permanece en el «museo imaginario» (Malraux) del público, y es eso lo que se rememora en estos filmlets. Pero lo que está ausente en ellos es el genio cinematográfico, la concepción, los contenidos y la riquísima complejidad multipolar, tan genuinamente fellinianos.

Lo que resta, pues, en estos anuncios son los signos. Puro manierismo. Ciertamente un arte ligado al barroco, pero en el cual la maniera de decir deviene más importante incluso que lo dicho. El anunciante ha comprado esto precisamente y nada más que esto: la «manera» de Toulouse-Lautrec, la de Mucha y la de Fellini. Además de su notoriedad como reclamo añadido al anuncio.

Habrá que considerar si ese manierismo de autor en los anuncios del Banco di Roma hace parte de su filmografía, aún poniendo entre paréntesis, si se quiere, obras maestras que han pasado a la historia del cine, como La dolce vita, Roma o Amarcord.

El caso del rediseño de la penúltima versión del símbolo-marca de Renault es parecido a los que acabo de citar. Para ese rediseño, la firma convocó al op'artista Vasarely. Este meditó el encargo y lo rechazó con la sugerencia de que su hijo, también artista, podría ocuparse de ello. Renault aceptó con la condición de que Vasarely validara el trabajo. Definitivamente, el rediseño es obra de su hijo, Yva$\mathrm{ral}^{3} \ldots$ pero Renault se olvida de ese detalle y presume oficialmente de Vasarely (valor añadido).

3 Yvaral es acrónimo de Vasarely. 
Realmente, existe una tautología que quiere que todo lo que hace un artista sea, intrínseca e inevitablemente, Arte. Esta ideología encontró su respuesta irónica en la célebre exposición de latas de conserva que ostentaban la etiqueta: Merde d'artiste, firmada por el autor. $\mathrm{O}$ aquellos anuncios publicados en la prensa parisina por el artista sociológico Fred Forest, que mezclaba arte y especulación ofreciendo «parcelas de terreno artísticas» con garantía de alta plusvalía. Lo cual era totalmente falso, claro.

El artista, desde el Paleolítico hasta hoy y sea cual sea su visión del arte, es el responsable total de su obra. No así el publicitario o el diseñador, que solo son responsables de las formas y el estilo, pero no del contenido, que es consecuencia de las directrices de marketing, de los objetivos del cliente.

\section{Interferencias}

En toda observación y reflexión se introducen interferencias, unas veces inconscientemente y otras de manera interesada. Son filtros psicológicos o intelectuales, trampas deformantes: los prejuicios, los partidos tomados de antemano, los apriorismos mentales, las teorías y las etiquetas.

En el debate que nos ocupa, aparecen también algunos de estos filtros que distorsionan la percepción directa y la comprensión de los fenómenos. Subrayamos aquí el problema de la generalización abusiva de las ideas. Veamos, como ejemplos, la consideración del pasado a partir del presente; la mirada del presente puesta en el pasado; las «ilusiones ópticas» en la percepción del Arte y de la Publicidad. Barreras que hay que derribar para ver claro.

\subsection{La generalización abusiva como enfermedad social}

Esta tendencia es tan abusiva como su contraria: el reduccionismo.

Ya sabemos que nada existe en estado puro. Y no vamos a reclamar estados de pureza para el Arte, la Publicidad y menos aún para el Consumo. De hecho, el mestizaje y la hibridación se imponen. Todo se mezcla, se entreteje, se enmaraña y se confunde. $\mathrm{Y}$ es así como se nos dice que los artistas recurren a la Publicidad como estrategia, para sí mismos y para sus obras; que la Publicidad recurre al Arte; que el Arte copia la Publicidad, etc. De este modo, se produce la devaluación de las palabras, o, a la inversa, la inflación del sentido. Y, al final, «todo es arte» -la Publicidad, la jardinería, la cocina, la peluquería o la cría de mascotas-; «todo es publicidad» -el Arte, la decoración, la moda, las catedrales-; «todo es consumo» incluso lo que no se consume-, porque «todo es marketing», «todo es mercado» y «todo es mercancía» -incluido el arte, la mierda de artista, los valores, las sensaciones, las emociones. 
En el ciclo sociocultural, la cultura se transforma en basura que se recicla en cultura que se transforma en basura que se recicla en cultura y así sucesivamente, tal como lo analiza el filósofo de la comunicación Vilém Flusser en una analogía implícita del circuito producción-consumo-destrucción-producción-consumodestrucción... y así hasta el infinito. ${ }^{4}$

Generalizando abusivamente, se ha llegado a decir que una catedral es el anuncio de sí misma. ¿Cómo es posible confundir un objeto inerte en el espacio con un mensaje persuasivo en los media? Una catedral, igual como una plaza de toros o un estadio de fútbol, una botella o un zapato son existentes en el entorno, y como tales se nos hacen presentes y al mismo tiempo nos informan de lo que son: su identidad, por la cual los reconocemos a través de la Forma. También es parte de su identidad la información que leemos en ellos y que forma parte de nuestra cultura. Información simbólica superpuesta a la Forma, o representada por ella; información funcional asimismo inherente a la Forma.

Esta información del objeto -simbólica o funcional- es aquello por lo cual lo reconocemos, porque está en nuestra memoria. Tenemos una memoria vertical simbólica de la catedral, que es un arquetipo. Una memoria circular simbólica de la plaza de toros. Una memoria rectangular simbólica del campo de fútbol. Y una memoria funcional de la botella como forma contenedora, y una memoria funcional del zapato como forma que se adapta a la forma del pie.

Esos objetos son objetos autorreferenciales. A diferencia de los anuncios publicitarios, se presentan y se significan a sí mismos, directa e inmediatamente -sin necesidad de medios interpuestos-. En este sentido, el objeto mismo es lo opuesto a un mensaje publicitario, porque este nunca se refiere a sí mismo sino a cosas in absentia. Una catedral dice «soy una catedral» y un zapato dice «soy un zapato». Pero un spot no dice «soy un spot»: dice Coca-Cola o El Corte Inglés, Vodafone, Lotería de Navidad o lo que haga falta. La Publicidad no es una cosa, es un lenguaje.

\subsection{El presente en el pasado}

Esta tendencia a mirar el pasado con los ojos del presente es tan engañosa e inútil como la que mira el presente con los ojos del pasado. El socorrido argumento de la pintura religiosa como anuncio es uno de los ejemplos recurrentes en el que proyectamos ideas $-\mathrm{o}$ deseos- del presente en el pasado. La pintura y la escultura religiosa o sagrada no son sino imágenes, representaciones de escenas y personas, que son declaradas «iconos», o sea figuraciones verídicas y no invenciones capri-

4 V. FLUSSER (2010): «Kitsch y poshistoria», La Comunicación. 10 voces esenciales, Barcelona, CPC Editor. 
chosas de los iconógrafos, que eran iluminados por la Gracia a la hora de sus visiones arrebatadas: los estados de éxtasis que inspiraban sus iconos. Obviamente, tales explicaciones son la primera parte de la instrumentalización de esas imágenes: ¿cómo sabía el pobre artista que aquello que pintaba era realmente así, un reflejo de las verdades invisibles o una pura imaginación?

Las imágenes religiosas no son publicidad en la misma medida que ellas no «hacen público» un mensaje, sino que solo lo muestran. No proclaman, ni explican ni difunden nada. No hablan. Son mudas. No funcionan por sí mismas como lo haga un cartel o un spot. Funcionan por medio de un ritual aplicado, que les es externo y que, a pesar de que ellas han sido convalidadas como verdaderas por los guardianes de la Fe, esto no es suficiente para que funcionen, es decir, para convertir a los infieles y descreídos.

Es entonces cuando se entra en la segunda parte de la ritualización, la liturgia, la instrumentalización de las imágenes por parte de quienes hablan por ellas: los endoctrinadores de la Fe que habrán de extenderla urbi et orbi. Propaganda Fide. No se trata de un hecho publicitario, pues sus mecanismos son otros. Se trata de una operación confesadamente propagandística llevada a cabo por misioneros de la Fe mediante la presencia de las imágenes, que son ilustraciones de la doctrina. «El ojo cree en lo que ve», decía Brunswicg, a lo que se une el principio Pictura est laicorum literatura: la literatura de los analfabetos. El uso de la retórica y los recursos de la coerción tremendista también tuvieron su rol aquí.

En el siglo XVII, un personaje fascinante, Athanasius Kircher, jesuita y científico alemán, hizo su fortuna en Roma mostrando en la iglesia a sus fieles asustados la primera visión «viva» del infierno. Kircher siguió la idea de la Biblia Pauperum, una táctica muy difundida en la Edad Media para acercar los fieles a la palabra de Dios, mediante el empleo de las imágenes, ya que la gran mayoría de la gente en la época era analfabeta. El jesuita integró a la cámara oscura una luz artificial interna (un candil potente) y una lente -que cumplían la función de la linterna y la lente del objetivo de un proyector actual-, transformándola en una especie de linterna mágica. Esto le permitía proyectar imágenes dibujadas a una distancia de hasta cien metros, se dice, que aparecían proporcionalmente ampliadas por el efecto de la lente.

Pero la sutileza del invento era aun más sorprendente. Para sugerir la sensación de veracidad y vitalidad a sus proyecciones infernales, utilizaba los recursos más increíbles, como el empleo de humo para dar impresión de movimiento a las figuras, o la inclusión de insectos raros (vivos) en sus imágenes del infierno que, ampliados cien veces, parecían monstruos diabólicos. Kircher hace así visible una imagen mental (la idea del infierno, de los demonios); emplea la simulación para 
hacer realidad un mundo totalmente ficticio. ${ }^{5}$ He aquí un acto intimidatorio, una coacción potente, aunque hoy nos parezca ingenua; un ejemplo de lo que no es Publicidad para aquellos que quieran verla en todo.

\subsection{El pasado en el presente}

La actitud opuesta a la anterior es aqulla que quiere ver en el presente los valores del pasado. El Arte en Andy Warhol es el ejemplo inevitable. Ven Arte donde hay marketing por detrás de la obra. Y ven Publicidad en su superficie.

Lo que hay en la obra de Warhol es otra cosa. Exactamente, la combinación de dos ingredientes: 1) cosas diseñadas del mundo del consumo, y representadas por el autor en sus obras, a través del diseño y 2) mediante las técnicas del diseño.

Lo que llamo «cosas diseñadas del mundo del consumo» son las que provienen de la civilización industrial ya periclitada. Son los objetos diseñados, producidos y reproducidos en serie y expuestos en los supermercados, como las latas de sopa Campbell o la botella de Coca-Cola; las marcas, etiquetas y logotipos de los productos de consumo; las fotografías de famosos extraídas de los medios de grandes tiradas. «A través del diseño» significa que Warhol trata estos elementos diseñados a su vez como diseños (gráficos) y no como arte pictórico. Y emplea para ello las técnicas propias del diseño: fotografismo, cartelización, tintas planas, colores primarios, serigrafía, fotomontaje, etc.

Estas observaciones nos llevan del Arte al Diseño -al que llamamos grafismo funcional porque, a diferencia del arte, «sirve para... »- Esta concepción, que está en la obra de Warhol, no proviene, pues, del Arte. Proviene de la escuela de la Bauhaus, que desde 1919 hasta 1933 en Alemania -y después en América- fusionó los oficios, la artesanía, el arte, la arquitectura y la investigación bajo la idea matriz de Diseño, ligada a la creatividad y la práctica proyectual. De ahí surgieron las disciplinas de diseño gráfico, diseño tipográfico, diseño industrial, diseño escenográfico, diseño publicitario, diseño de indumentaria, etc...

Lo que hay es básicamente Diseño, pero solo se quiere ver Arte en la Publicidad. Esta fijación se manifiesta también en el lenguaje de las agencias, que llaman «director de arte» a quien de hecho es director de diseño, y «artefinalista» a quien realiza el estadio final de los diseños para ser reproducidos. Esta polarización en el Arte no nos deja ver las muchas influencias extra-artísticas en la Publicidad -que son las más-. En los anuncios hay también grafitis, pictogramas, cómic, manga, emoticones, señales de tráfico, neón, moda, estampas populares, dibujos infantiles, fotos históricas, imágenes científicas, surrealismo, esquemas, diagramas, tipografías, lenguaje SMS, fantasías, figuras del Oeste, dibujos animados, fotogramas TV,

5 J. Costa (2008): La fotografía creativa, México, Ed. Trillas. 
caricaturas, geometría, videojuegos, humor, terror, escándalo, intimismo, psicodelia, kitsch y todas las estéticas imaginables. Que no son por lo general tratadas como arte, ni siempre son arte.

Si por un lado caemos en generalizaciones abusivas, por el otro lo hacemos en el mayor reduccionismo. Veámoslo.

\subsection{Percepción: contemplación versus contingencia}

Otra de las interferencias que denunciamos aquí es aquélla que quiere ver (o mirar) un anuncio como se mira un cuadro.

El Arte funciona por un previo interés, o por lo menos una predisposición: que supone una atención por los libros y las reproducciones, o bien por acudir a visitar la galería de exposiciones y el museo, e incluso a veces permanecer en la fila de espera largo tiempo, tal como sucede en las grandes exposiciones y en los grandes museos.

Otro aspecto ligado al arte, además del interés por el mismo, es la contemplación. La calidad de esta se mide por el tiempo que el individuo dedica su atención a contemplar y explorar un cuadro; puro placer con sus miradas parciales de cerca para admirar el detalle y sus distanciaciones para captar el efecto de conjunto; con la búsqueda del significado simbólico -si lo hay- y el disfrute estético.

La Publicidad, por el contrario, funciona por la contingencia. Uno se topa con los anuncios o no, aleatoriamente. Por eso, para poder sorprendernos, el anuncio debe llamar la atención, capturar la mirada y, si es posible, retenerla para poder transferirle el mensaje. Y es justo por esta función choc, este empeño en sorprender y llamar la atención como sea, como el destinatario solo recuerda lo que le sorprendió e ignora la marca que se anunciaba.

El anuncio tiene sus destinatarios precisos. El cuadro, no. No se contempla un cuadro como se mira un cartel o un anuncio. Porque, además, el lenguaje del Arte es simbólico, ambiguo, complejo y abierto a las interpretaciones. Contemplar un Vermeer o un Dalí no son buenos ejemplos para demostrar cómo se percibe un anuncio. Empezando por la actitud voluntaria de desplazarse al museo versus lo contingente y aleatorio del encuentro con el anuncio. Además, viendo un Vermeer o un Dalí, la mirada que se desplaza por los itinerarios imaginarios de la superficie del cuadro puede construir un relato, una cierta historia, un argumento. Pero esto no ocurre fuera del Arte no académico, no figurativo, no romántico ni descriptivo. ¿Cómo buscar elementos retóricos y argumentales en los Girasoles de Van Gogh, en las superficies cromáticas de Rothko, en los trazos de Pollock o de Hartung? ¿O acaso todo eso no es Arte?

El error de partida no es comparar Arte y Publicidad, sino ciertas imágenes artísticas y ciertas imágenes publicitarias. El Arte no es solo eso, igual como la Publicidad no son solo las imágenes que ilustran los anuncios. Y, recordémoslo, si la imagen pictórica funciona sin código, el anuncio funciona por la alternancia no 
código (la imagen) código (el texto): un doble juego dialéctico, sensitivo e intelectual; el reconocimiento directo de la forma y el intelectual desciframiento textual.

La Publicidad está relacionada con la vida cotidiana, los medios de difusión masiva, el espacio público y privado, y la contingencia. El Arte lo está a los museos espacio acotado-, a la contemplación y a la conservación.

Esta postura sesgada, que no distingue entre contemplación atenta, a veces fascinada que el Arte propicia, y la contingencia -y a veces inoportunidad- con que nos sorprende la Publicidad, a menudo de un simple vistazo a gran velocidad desde el coche, me recuerda la tenacidad de ciertos semiólogos como René Lindekens, que se empeñan en aplicar el instrumento de análisis del mensaje textual para que sea estudiado con él el mensaje icónico. Sin advertir algo tan simple como: que no se escribe un texto como se produce una imagen; que el primero requiere haber sido alfabetizado, y no el segundo; que descifrar un texto es un ejercicio intelectual complejo y percibir imágenes es reconocer formas directamente; que el texto es secuencial y la imagen, instantánea; que el escrito obliga a un ejercicio mecánico de los ojos y la imagen nos libera de todo condicionante fisiológico; que el escrito empieza en un punto de la linealidad continua y termina en otro punto final, y la imagen no tiene principio ni fin y cada quien puede explicar lo que está viendo en ella empezando en un punto o en otro y siguiendo recorridos diferentes.

No. No es lo mismo contemplar a placer, libremente, selectivamente, o ser sorprendido, perseguido y embestido por la omnipresencia de los anuncios que invaden el entorno y el fluir de la vida personal.

\section{6. ¿Arte o Diseño?}

Si nos fijamos bien, un anuncio es claramente un producto - un mensaje-diseñado. Entendemos por «diseñar» el siguiente proceso: 1) la concepción de ese mensaje como proyecto; 2) la elección y la articulación de los elementos visuales (gráficos, fotográficos, tipográficos, cromáticos), y 3 ) la composición con ellos del anuncio, con el fin de hacerlo eficaz tomando como referentes unos objetivos y unos condicionantes declarados por marketing en un brief o pliego de condiciones técnicas.

El mensaje diseñado - sea publicitario o no- tiene algo de la teoría de la Forma que salta a la vista. Es evidente que todo lo que está en ese mensaje no es obra del azar, sino de una voluntad de organización y de una finalidad comunicativa. Todo diseño implica lo que los clásicos llaman «composición» en la obra pictórica, y que en diseño llamamos «estrategia de comunicación» o «retórica visual». Ello son tanto la distribución de los elementos gráficos como las líneas de fuerza subyacentes, la arquitectura que los sustenta, el contraste y la jerarquización de los «pesos» en función del impacto buscado, la expresividad o la seducción. Así, el mensaje 
tiene algo también de teatral o de espectacular. Es la mise en scène y todo lo que ella conlleva: casting, ambientación, relato, arquetipos, decorado, atrezzo, etc.

En el orden de la sociología, el diseño conjuga dos factores: la psicología de las motivaciones y los códigos correspondientes a su target. Y en lo formal se armonizan los lenguajes icónico y lingüístico (textual). El conjunto, considerado en su función comunicativa, puede observarse como la superposición, en el Mensaje, de un mensaje denotativo o semántico y un mensaje connotativo o estético. Que corresponden, respectivamente, a lo que se dice y a cómo se dice para convencernos o seducirnos.

Esta presencia irreductible del diseño en el mensaje publicitario se revela en todos sus detalles. En el caso del audiovisual (4D), el predominio del movimiento y la acción sobre la forma estática (2D) introduce el elemento temporal, el relato, la secuencialidad, el discurso diacrónico. Algo asimismo diseñado.

\section{La única evidencia está en los hechos}

Lo que queda por explicar en este último capítulo es de qué modo he traído el Diseño en el debate, cuando no estaba previsto en la mesa sobre Arte, Publicidad y Consumo. Los comentarios sobre Warhol son un referente, pero tenemos que hablar de método.

He empezado esta ponencia por anotar la primera intuición sobre A, P, C. Después, he anotado ciertas observaciones sobre A, P y C, así como la aparición de los signos del artista en los anuncios, y he tratado de las interferencias de los filtros intelectuales que deforman la comprensión de la realidad. Así he llegado al Diseño.

Hasta aquí, todo lo dicho es «cosa mentale», como decía Leonardo. Ha llegado el momento de convocar al observador con sentido crítico y espíritu fenomenológico. Así que, aquí estamos. Olvidemos las palabras, los conceptos, las teorías y todo lo que ha sido escrito más arriba. Y, como quería Husserl, vayamos directo a la cosa. Pongamos entre paréntesis lo que sabemos o creemos saber y, así descondicionados, dejemos que se produzca la contingencia y la sorpresa del encuentro con la Publicidad, en el más vulgar y corriente discurrir de lo cotidiano.

Para el siguiente ejercicio, he olvidado gustosamente buscar los anuncios en los libros que tratan de Publicidad, las revistas ilustradas, los books de las agencias y creativos y los Festivales publicitarios. Como todos los días, he hojeado el periódico y, cuando viene con él, el suplemento en forma de revista; he fisgoneado la televisión. Pero no me he interesado por las noticias sino por los anuncios.

La «ficha técnica» de esta encuesta casera hecha por el hombre corriente de la calle y no por el experto abarca los días 16 al 20 de diciembre de 2010 para el trabajo de campo. He consultado tres periódicos (El País, El Periódico y La Vanguardia) y dos suplementos, y casualmente, porque me llegó por el correo, una revista actual de Publicidad (Control). 
Tabla explicativa de la encuesta

\begin{tabular}{|lcc|}
\hline Soporte & Fecha & $\mathrm{N}^{\circ}$ de anuncios \\
\hline El País & 16.12 & 21 \\
El Periódico & 17.12 & 22 \\
La Vanguardia & 18.12 & 40 \\
El País & 18.12 & 45 \\
La Vanguardia & 19.12 & 36 \\
Magazine L.V. & 19.12 & 51 \\
El Mundo & 19.12 & 50 \\
Suplemento E.M. & 19.12 & 34 \\
El País & 19.12 & 36 \\
El País Semanal & 19.12 & 59 \\
El Periódico & 20.12 & 24 \\
Control & $\mathrm{n}^{\circ} 574$ & 26 \\
\hline \multicolumn{2}{c}{ TOTAL } \\
\end{tabular}

He contabilizado un total de 444 anuncios. La mayoría a tamaño de una página, media página (vertical y horizontal) o formato semejante, y dos anuncios de doble página. He dejado fuera de mi interés los anuncios por palabras, las secciones de oferta y demanda, los anuncios de las secciones de espectáculos y los de masajes, relax, contactos, etc... a pesar de que todos ellos son anuncios y, por tanto, deberían ser considerados en un estudio que pretendiera ser exhaustivo; igual como debería incluirse el product placement en audiovisuales, los transportes públicos y privados que ostentan publicidad, los anuncios en las entradas de los espectáculos, los toldos, parasoles, mesas, sillas y mobiliario de los bares, etc., pues todo esto es publicidad y todo incide de algún modo en el público. Al fin y al cabo, esto es lo que nos llega en la contingencia. 


\subsection{Resultados}

Entre los anuncios en prensa diaria y semanal aparecen dos alusiones directas al Arte: 1) Maker's Mark, con el eslogan «Una verdadera obra de arte»; este anuncio copia los relojes blandos de Dalí sobre la botella y el vaso de wisky. 2) Sculpture, con el texto destacado «Happy New You» y más pequeño: «Propósito $\mathrm{n}^{\mathrm{o}}$ 7: conseguir que se interese por el arte». Imagen: una chica de perfil mirando al espectador, vestida con tejanos, situada supuestamente en una galería o museo junto a una escultura de tamaño natural; la modelo imita el gesto de la escultura; en primer plano, una mano con una cámara muestra en el visor el detalle de la cintura y la cadera de la chica.

Aparte de estos dos registros explícitamente referidos al arte, entre 418 anuncios de periódicos y suplementos, encuentro entre los 26 de la revista Control (diciembre 2010) un anuncio del periódico La Razón que muestra en gran tamaño un hermoso violín acompañado del eslogan «Seguimos in crescendo» referido metafóricamente al arte de la música para simbolizar el aumento de lectores.

\subsection{En síntesis}

Esto es todo lo que en estas fechas he encontrado que tenga que ver con el arte más o menos forzadamente-. Cierto que no he tomado notas sobre lo visto en televisión, ni he recurrido a internet, ni he salido a buscar publicidad exterior. $\mathrm{Me}$ he limitado a hacer lo que sí hago todos los días. Es el modo de no sesgar la encuesta: comportándome de modo habitual para tratar de hacerlo como hace todo hombrecito de la calle, más absorbido por sus cosas que por los anuncios.

Como comentarios adicionales, puedo añadir que la mayor parte de anuncios de relojes muestran el producto en primer plano a gran tamaño (Swatch, Hamilton, TAGHeuer, Tous, Omega, Tissot, Breguet, IWC, Banne \& Mercier, Rado, Certina, Alain Afflelou, Maurice Lacroix). El sector de perfumería y cosmética tiende al blanco y negro para los productos masculinos; los destinados a la mujer se inscriben en el kitsch (Nina Ricci, Aire Loco Loewy, J. Del Pozo Ambar). Otros prefieren la sencillez y muestran los elementos indispensables (Tous, Chanel). En los anuncios hasta aquí considerados predomina el buen gusto e incluso refinamiento, lo cual no es tan corriente en los grupos siguientes.

Señalemos que abundan los anuncios de los propios medios y sus promociones, así como destaca la presencia repetida de El Corte Inglés, Viajes Barceló, Gobierno de España, Viajes Halcón, Air Europa y, en menor medida, Telefónica, Movistar, Faber-Castell, Selecta San Miguel y Viajes Iberia. Otra tipología de mensajes son los «anuncios-escaparate», que se limitan a mostrar cantidad de productos con escasa fotogenia (Hipercor, Miró, Gala, Carrefour, Toys Rus, Caprabo, Opencor, Alfaguara, Molino RBA, Exposición de Símbolos de Franco, Fnac, 40 Principales, 
Fotoprix, Decathlon, La esfera de los libros, Ofiprix, Unidad Editorial, Ediciones Viñetas, El discurso del Rey, Rabat, Torrons Vicens, Maestros Jamoneros SA).

\section{Conclusiones}

Este es esquemáticamente el balance de una encuesta tan casera y sencilla como se quiera, pero que refleja la realidad publicitaria en una foto fija del devenir de la vida cotidiana «iAh, la vida es cotidiana!», decía Laforgue.

1. La ausencia de Arte en la Publicidad examinada en esta muestra es evidente. Tanto como lo es la presencia del Diseño (bueno y malo). Comprobarlo está al alcance de cualquiera todos los días en su cursus vitae... mientras el observador quiera mantener esta distancia que lo asemeja a cómo «la gente» percibe los anuncios.

2. El experimento referido en el último capítulo demuestra lo que demuestra. Pero no más. No demuestra que, en efecto, existen mejores ejemplos que los que aquí ha traído el azar, ni que la historia de la Publicidad cuenta con una hoja de servicios llena de muestras de alto valor estético que son un reflejo de su devenir. Que sin duda han existido y existen. La pregunta es: ¿dónde?

La respuesta es: donde los publicitarios y los interesados los muestran, es decir, en las revistas especializadas, los festivales, los books de las agencias y los creativos, los libros de diseño. Pero muy difícilmente entre la cascada de anuncios que nos inunda día tras día en el curso de nuestras vidas de ciudadanos corrientes sobrecargados de problemas que nos acucian.

Los ejemplos que he citado en este artículo acerca de los grandes cartelistas de los siglos XIX y XX están en los museos y en los libros de historia de la Publicidad. Los filmlets de Fellini, que tuve el placer de conocer en estas Jornadas de Madrid, los vi junto con las aportaciones de otros ejemplos que equiparaban arte fotográfico o tipográfico y anuncios. $\mathrm{O}$ sea, demostraciones cuidadosamente seleccionadas y comentadas en el marco de un encuentro de especialistas e interesados.El colofón lo pone Lotte H. Eisner: «Lo más grave es el hecho de que el valor artístico de la publicidad no es determinante para su eficacia».

\section{Referencias bibliográficas}

J. Costa (2008): La fotografía creativa, México, Ed. Trillas.

V. FLUSSER (2010): «Kitsch y poshistoria», La Comunicación. 10 voces esenciales, Barcelona, CPC Editor.

A. MOLES (1977): Theorie des actes, Tournai, Casterman.

- (1976): Micropsychologie et vie quotidienne, París, Denoë1/Gontier. 